\title{
Atendimento psicológico ao paciente cirúrgico: O serviço de psicologia da área cirúrgica do HUAP
}

\author{
Mariana Derze Rodrigues, Claudia Porto Gonçalves, \\ Roberta Freire Cardoso Meireles*, José Henrique Valentim** \\ e Paulo Roberto Mattos da Silva***
}

O projeto permanente de extensão "Serviço de Psicologia da Área Cirúrgica - GSI/HUAP" (atendimento psicológico a pacientes cirúrgicos), desenvolvido de forma ininterrupta desde 1987, sob a coordenação dos professores Paulo Roberto Mattos e José Henrique Valentim, tem a perspectiva de integrar à matriz de trabalho extensionista as dimensões do ensino - tanto na esfera da graduação quanto da pós-graduação - e a pesquisa de forma continuada. Assim, a intensificação do sofrimento psíquico, derivado da própria patologia orgânica, demanda atenção que extrapola a especificidade do saber médico, bem como formas de intervenção pautadas tão-somente na vertente assistencial, criando espaço de atuação que reproduz o tripé básico da instituição universitária. Os objetivos foram: criar um espaço de confluência e integração de diversos saberes sobre a dimensão patológica do existir humano, nas suas múltiplas inscrições; ampliar o horizonte das possibilidades de tratamento por parte dos profissionais envolvidos com a tarefa; promover uma formação no campo psicológico, tanto em nível de graduação quanto de pós-graduação, que atenda às exigências atuais em termos da criação de novas estratégias de ação terapêutica e a familiaridade com o trabalho científico de natureza transdisciplinar. Como metodologia utilizamos entrevistas psicológicas com pacientes internados, discussão e supervisão de casos, definição de estratégias de atendimento, participação em reuniões clínicas das diferentes especialidades médicas. Os resultados foram a contribuição à formação de alunos de graduação em psicologia, atendimento integral a pacientes internados no Hospital Universitário Antônio Pedro e desenvolvimento de trabalho transdisciplinar com equipes de saúde da instituição.

* Estagiários do SPAC e alunos do curso de graduação em Psicologia da UFF.

** Professor Adjunto do Depto de Psicologia da UFF e coordenador do SPAC. Endereço: Av. Visconde do Rio Branco s/nº, Campus do Gragoatá, Bloco “O” sala 310 - São Domingos, Niterói - RJ. Tel (21) 26295018 - E-mail: valentim@vm.uff.br

**** Professor Adjunto do Depto de Psicologia da UFF e coordenador do SPAC. 
